How native and non-native speakers of English interpret unfamiliar formulaic sequences from Georgette Heyer's novels

Alison Wray (corresponding author)

Centre for Language and Communication Research

School of English, Communication and Philosophy

Cardiff University

John Percival Building

Colum Drive

Cardiff, CFIO 3EU

wraya@cardiff.ac.uk

Alison Wray is a Research Professor in Language and Communication at Cardiff University. She holds a BA and D.Phil from the University of York, UK. Her main contribution to research has been in the domain of formulaic language, including two monographs (2002 and 2008), the first of which won the 2003 book prize of the British Association for Applied Linguistics.

Huw Bell

Language, Linguistics and TESOL

Manchester Metropolitan University

227 Mabel Tylecote Building

Cavendish Street

Manchester, MI5 6BG

h.bell@mmu.ac.uk

Huw Bell is a Senior Lecturer and researcher in applied linguistics at Manchester

Metropolitan University. He is currently working on a project examining the teaching of

formal grammar in primary schools. Other research interests include the LI and L2 lexicon.

Katy Jones

Centre for Language and Communication Research

School of English, Communication and Philosophy

Cardiff University

John Percival Building

Colum Drive

Cardiff, CFIO 3EU

jonesKSI@cardiff.ac.uk

Katy Jones is a researcher and part time lecturer in Language and Communication at Cardiff University. She holds an MA from the University of Sussex and a PhD from Cardiff University. She is currently involved in several research projects, including investigating the role of the noun phrase in (digital) language development, and examining the exploitation of (in)definiteness in persuasive discourse.

Word count (excluding title page, tables, appendices and figures, but including abstract and references): $\mathbf{6 3 3 5}$ 


\title{
How native and non-native speakers of English interpret unfamiliar formulaic sequences from Georgette Heyer's novels
}

\author{
Alison Wray (Cardiff University) \\ Huw Bell (Manchester Metropolitan University) \\ Katy Jones (Cardiff University)
}

\begin{abstract}
This study examines whether native and non-native speakers faced with unfamiliar formulaic expressions use the same tactics for working out what they mean. The test items needed to be semantically opaque, used in an authentic context, and unknown to all participants. Ten obsolete expressions were selected from the historical novels of Georgette Heyer. First language English speakers and UK-resident classroom-taught learners of English as a foreign language were individually presented with the expressions in their original context, and asked to work out what they meant. Analysis of their comments revealed that the native speakers deployed significantly more context and analogy. Meanwhile, the non-native speakers were much more likely than native speakers to refer to individual unknown words. Whilst it seems that first language users take a more holistic approach to linguistic input than classroom-taught second language learners do, the findings may suggest that learners adopt increasingly 'native-like' strategies as proficiency increases.
\end{abstract}

Key words: formulaic language; idioms; language learning; comprehension; analogy; context

\section{Introduction}

\author{
MAGGIE The wife of a board member died and Will asked me to send flowers. I wrote \\ on the card, 'I'm so sorry about your loss. LOL.' \\ JIM LOL? \\ MAGGIE I thought it meant 'lots of love'.
}

(The Newsroom, Series I, Episode 6, HBO, 20I2)

When we first encounter a new expression, how do we work out what it means? If it is not directly analysable, as with LOL, we will either have to ask someone, or make a guess. A guess will be based on two possible types of information-internal cues (what could the Ls and the $O$ reasonably stand for in this context?) and external cues (what do others who use this expression appear to mean?). Sometimes, neither type of cue is sufficient, and, just as with single words, individuals can come to different conclusions that may remain undetected until some incident exposes a misunderstanding.

The same can happen when the components of the expression are more transparent. A person unfamiliar with kick over the traces, and seeing it in the sentence in Example I would have to use context to work out the likely meaning.

Ex.I

At the age of sixty, Walter kicked over the traces and ran away to Brazil'

\footnotetext{
' Example taken from http://idioms.thefreedictionary.com/kick+over+the+traces
} 
Walter did something (ran away) in the latter part of his life, and the deed was tantamount to kicking over the traces. So, what might it mean? The main lexical indicators are kick and traces. Taking kick over to have an abstract meaning founded on an image of physical action, several options are possible: kicking a ball over a fence or over to a person, kicking one's foot over a high object, or covering something up by kicking dust, leaves or other objects over it. To understand which sort of kick over it is, we need to understand what traces means. There are two options. The more frequent meaning is marks, signs or vestiges as in there were no traces of a struggle. The less frequent meaning is straps attached to the harness of a horse, and it is this meaning that applies in the idiom:

When the animal becomes upset, it may well kick out and end up stepping over the traces. At that point the driver has little or no control in steering or stopping. A person who rebels against convention and acts in what society would consider an unseemly manner has kicked over the traces.

(http://idioms.thefreedictionary.com/kick+over+the+traces)

Clearly, a problem will arise in understanding the metaphorical meaning of kick over the traces if the less frequent meaning of trace is not known or is not chosen. Nor will it necessarily be obvious what has happened, since the more common meaning of trace can also offer a plausible meaning for the expression. Someone who does not want to leave any footprints might well kick dust over them. Perhaps, then, when Walter kicked over the traces he covered up his tracks. He made himself disappear when he went to Brazil, so that no one could follow him. Two people could potentially interact successfully for some time with different interpretations of this idiom before anything in the usage or context revealed the non-alignment. This example shows how when we attempt to infer the meaning of unfamiliar, non-literal expressions in use, we have to manage a range of uncertainties, ambiguities and potentially conflicting information. Mistakenly choosing the more frequent meaning of traces is only possible because it renders a plausible alternative interpretation. Thus, context, analogy, precedent and pragmatics play their role alongside frequency. Suppose the more common meaning of trace had not rendered a plausible reading, but the infrequent meaning was also not known. How would one then work out its meaning? This is the question that this article addresses.

\section{Why idioms are difficult to learn}

Idioms differ from other multiword expressions in two main ways. Firstly, they have a form that is recognised within a speech community as being associated with a particular nonliteral meaning (Laval \& Bernicot, 2002). A useful rule of thumb for judging whether an item is an idiom or not is to ask whether, knowing the meaning, one could possibly come up with the form if one didn't know it already. By this reckoning, dress someone down, throw the book at someone and look a gift horse in the mouth are idioms, where dress someone up, throw a ball at someone and look a gift salesman in the eye are not. The reason is that the latter mean what they appear to mean, whereas the former are a conventionalised way of expressing a meaning different from the surface one.

Secondly, their form is fixed - at least to an extent. In fact, although idioms need some core static component, few of them are completely immutable (Moon, 1998). Function words, adverbs and adjectives are likely to be stable, as is the verb (though not its morphology). Sometimes nouns are fixed. But often the expression is kept flexible for different referents through a noun phrase slot (e.g. $N P_{1}$ give $N P_{2}$ a piece of $N P_{1}$ 's mind). 
Nippold (2006: 370) locates idioms along a continuum of difficulty for learners, from those that are 'transparent and frequently occur in spoken and written language' to those that are 'opaque and rarely occur in the language'. Transparency here does not mean that the words have their literal meaning, but rather that it is possible to map the elements in the expression onto components of the non-literal meaning. To illustrate, Nippold contrasts go by the book, where the 'book' can be imagined to contain the rules that are complied with, with go by the board, where the meaning of 'be discarded' cannot be mapped so easily onto the internal components.

Despite Nippold's implication, transparency and frequency are not strongly associated. They are at least independent if not in an inverse relationship. As with individual lexical items, frequency protects idiosyncratic forms and meanings from being regularised, meaning that frequency and irregularity are typically associated (Rumelhart and McClelland, 1986: 240). Low transparency does not inevitably result in greater difficulty with comprehension. Other than in citation contexts, the core arbiter of comprehensibility is a third variable, context. Indeed, the natural learning of idioms requires inference from their usage. Although, as we saw earlier, it is not an infallible process, context will generally trump transparency. If that were not the case, then when we encountered a word string that was ambiguous (e.g. skating on thin ice) we would favour the easier, literal reading, even if it did not make sense. It is only context that tells us when such an expression is intended metaphorically rather than literally. The incongruence that arises in metaphorical usage requires the hearer or reader to apply pragmatics to work out a plausible meaning, according to Grice's (1975) principle of cooperation - that is, the assumption that the speaker or writer intended to be meaningful.

Thus, the survival of idioms in a language is dependent on the capacity of hearers and readers to suspend disbelief in relation to the literal meaning and look for a metaphorical meaning. However, we do not have to rerun that process every time, for idioms seem to be rather easy to remember. The initial impact of the image, and the effort taken to tease out the intended meaning, may make them more salient and thus more memorable. Certainly something is defying the typical patterns of learning, whereby frequency of exposure builds up familiarity (Taylor, 2012). Idioms are too infrequent for that to be the explanation. Take $a$ rain check occurs just 19 times in the 450 million word Corpus of Contemporary American English (COCA) and kick over the traces occurs 5 times - by way of comparison hegemonic occurs I0II times and ontological 837 times.

\section{How idioms are learned}

\section{I Idiom learning in the first language}

Idiom learning in the first language needs to be seen in the context of children's approach to language acquisition more generally. It is possible to explain the progression of children's general language acquisition on the basis of the recycling of the multiword strings to which they are exposed, along with an alertness to the relative fixedness of components with them, so that flexibility can be introduced exactly where it is permitted (Peters, 1983). Lieven et al. (2003) and Dąbrowska and Lieven (2005) found that an infant's novel expression almost entirely entailed deploying simple operations (embedding and chaining) to reuse previous input from the mother. Wray (2002) links the holistic approach to first 
language acquisition to the ubiquity, tenacity and functional importance of formulaic material in a language. As Tomasello (2003: I0I-102) puts it,

It turns out that, upon inspection, a major part of human linguistic competence much more than previously believed - involves the mastery of all kinds of routine formulas, fixed and semi-fixed expressions, idioms, and frozen collocations. Indeed one of the distinguishing characteristics of native speakers of a language is their control of these semi-fixed expressions as fluent units with somewhat unpredictable meanings.

Idioms, then, are part of a much larger set of formulaic units in a language. However, there is a difference in how they can be acquired. Tomasello, Lieven and Dąbrowska base their claims on usage-based models of language acquisition, in which frequency of exposure is key:

Speakers are exquisitely sensitive to the language that they encounter, noting the uses of words, their collocations and their syntactic environments, the constructions and their special semantics and conditions of use, as well. (Taylor, 2012: 283-284).

But, as noted above, idioms are not frequent enough, or flexible enough, to be learned in this way. Vulchanova et al. (20II) found that by age ten, children were still unfamiliar with $50 \%$ of the common idioms on which they were tested. Given the semantic impenetrability of idioms, inferential learning from context will only be possible if there are plenty of examples that between them enabled the child to identify patterns in their usage.

In lieu of adequate exposure to idioms, children seem to do two things. One is to set them aside for later. As with unknown words, if they are anticipating decoding them on the basis of frequency, then they can only note that they saw them, and must then wait for more information before working out what they mean. The other way children handle idioms is by bringing to bear on them their current knowledge of the language and the world - a world in which figurative language does not yet feature all that strongly. Laval \& Bernicot (2002) found that six-year old children struggled to interpret idiomatic expressions non-literally. However, nine-year olds performed better, by virtue of relying heavily on the context. Meanwhile, adults were able to interpret expressions non-literally even in the absence of context. Vulchanova et al (20lI) found that ten-year-olds offered literal readings of unfamiliar idioms - but they were not presented in a context of use. This meant that the children did not have any opportunity to recognise incongruence between a literal meaning of the idiom and how it was used.

If someone unfamiliar with the expression skate on thin ice was shown it without any context, why should they not take it literally? In fact, in contextualised uses, both the literal meaning and the implications from context must operate together. In order to notice that a word string is incongruous and note that the meaning cannot be resolved, and register it as a fixed, or partly fixed expression, one must in some way interrogate it.

\subsection{Idiom learning in a foreign or second language}

One of the most persistent puzzles in applied linguistics is how learning another language can be so difficult, given that the same individual has already mastered one language (Wray, 2008c). A range of potential explanations has been extensively explored over the years, 
including a brief window (critical period) during which native-like proficiency can be achieved; one-off developmental calibrations that are anchored in the first language and do not change subsequently; differences in the extent and quality of exposure to another language; and differences in how the speaker is positioned emotionally and socially in relation to it (see Wray, 2002 for a discussion of these alternatives). The research findings are complex and often contradictory, not least because no two learners are quite the same. The claim that post-childhood language learning can never approximate native-like patterns is clearly overstated, particularly if one separates out phonological mastery from everything else. However, just what enables a subset of learners to reach native-likeness remains unclear.

Post-childhood language learners have a number of cognitive advantages over infants, including much more mature metalinguistic awareness and a wider range of means to record and return to input material. Perhaps for this reason, they are typically found to take an over-regulated, piecemeal approach that seeks a greater measure of regularity and logicality than natural languages actually display. Wray and Grace (2007) review and discuss evidence that languages spoken only by native speakers accumulate irregularities (see also Bergen, 200 I; Wray, 2008a), while, conversely, languages become more regular if they are used extensively by post-childhood second language learners. In lingua franca contexts, expressions with a non-literal meaning have a disproportionate potential to derail communication (e.g. Seidlhofer, 20I I; Mackenzie, 20I4).

\section{Investigating how unknown idioms are interpreted}

Using a think-aloud method, Zuo (2008) investigated how Chinese learners of English of different proficiency levels tackled the comprehension of unknown idioms. She identified ten strategies. By far the most prevalent, at $62.5 \%$ of all attempts at meaning making, was what she terms 'making schematic inferences' - that is, drawing on the contextual information in the passage containing the target item. Zuo found that the participants with higher English proficiency used more context than those with lower proficiency. The investigation below is in some ways similar to Zuo's. However, the aim was to compare the strategies of native and non-native speakers.

\section{I Selecting suitable idioms expressions}

Three possible approaches could be taken to investigate whether first and post-childhood second language users take the same approach when decoding an unknown idiom. One is to compare native speaker children with non-native speaker adults. Here, one could anticipate that expressions known to native speaker adults might not yet be known by either set of participants. However, as we saw earlier, comparing children with adults would introduce many unwanted variables, including cognitive maturity and knowledge of the world. A second option is to give native and non-native speaker adults stimuli from an artificial language. But this is ecologically far removed from real, functional language learning. The third possibility is to find stimuli with formulaic characteristics that have not been 
encountered by adult native or non-native speakers before, but that native speakers will nevertheless accept as legitimate in their language. ${ }^{2}$

Such items can be found in the work of the British author Georgette Heyer (1902-1974), thirty-four of whose novels are set in the Georgian and Regency period. Heyer made a particular study of the turns of phrase used at the time, and incorporated examples into the dialogue of her characters (Hodge, 1984: 39-40). The expressions are semantically opaque, usually because they are metaphorical, and thus they signal themselves - to adults at least as formulaic. Yet since Heyer does not explain them, the reader has to infer their meaning somehow. Consequently, a native speaker who reads Heyer's Georgian and Regency novels undergoes a similar experience to that of a proficient non-native speaker reading works in the second language in which there are formulaic expressions that are unfamiliar. Example 2 gives a flavour of Heyer's text, from The Toll Gate (1954).

\section{Ex.2:}

Chirk dived a hand into his pocket, and drew forth a snuff-box. It was a handsome piece, as its present owner acknowledged, as he offered it, open, to John.

'Took it off of a fat old gager a couple o' years back,' he explained, with engaging frankness. 'Prigged his tattler, too, but I sold that. I'm a great one for a pinch o' merry-go-up, and this little box just happened to take my fancy, and l've kept it. I daresay l'd get a double finnup for it, too,' he added, sighing over his own prodigality. 'It's worth more, but when it comes to tipping over the dibs there ain't a lock as isn't a hob-grubber.'

Depending on whether expressions are counted as a single item or several words, and which words are considered to be opaque (for example, are 'pinch', 'double' and 'lock' to be taken literally or not?- see later discussion), between $4 \%$ and $6 \%$ of the text will be unknown to most native speakers. According to Laufer and Ravenhorst-Kalovski (2010) a reader must understand between $95 \%$ and $98 \%$ to successfully understand a text, though Heyer arguably mitigates the risk of losing her reader by providing plenty of context, and by only using these expressions within speech. That is, they are part of the language of her characters, not her narrative and do not carry the plot.

\subsection{Participants}

Twenty-three non-native speaker ${ }^{3}$ participants were recruited. They were overseas undergraduates, postgraduates and academic visitors at two British universities. Their proficiency on arrival in the UK had varied from around IELTS 6.0 to near-native, and ten first languages were represented. In the absence of an up-to-date measure of their proficiency that would take into account their learning since arriving in the UK, an informal task was compiled to examine, specifically, their familiarity with some common English

\footnotetext{
2 If a phrase is unfamiliar to a native speaker, it fails one of the tests normally applied to establish formulaicity (Wray and Namba, 2003; Wray, 2008a): having a known conventionalised meaning. But other tests will confirm it as formulaic.

${ }^{3}$ Our choice of the term 'non-native speaker' is deliberate, even though in some contexts it underrates the legitimacy of the second language speaker as an expert user. We are interested in whether the fact of learning a language after infancy and in a classroom impacts on how unknown expressions are interrogated.
} 
idioms (see Appendix I). ${ }^{4}$ The non-native speakers' scores spread fairly equally from 0 to 14 (see Figure I). The mean was 8.48, the median 9.

Seventeen native speakers - eleven undergraduates and six teachers of English as a foreign language at the same universities - also participated. They also took the English idiom completion test, and all of them scored 15 out of 15.

-Figure I about here-

\subsection{Design}

From a longer list assembled from Heyer's novels The Tollgate, The Black Moth and The Reluctant Widow, ten expressions were selected ${ }^{5}$ that displayed features likely to be of interest (Table I). Most of the expressions were figurative, but two were not. Rather, they were literal, but used words that the participants would need to understand in order to realise that fact: compare prigged his tattler - stole his watch (Partridge, 1973) in Example I.

\section{-Table I about here-}

The expressions, written in bold, were typed onto paper, in their original paragraph, lightly edited to make the text freestanding (see Appendix 2). Participants were interviewed individually in a quiet room, and were audio-recorded as they read the passages aloud and attempted to explain the expressions. The participant saw the items in one of two different orders, so as to reduce the impact of fatigue, practice or strategy-development on the combined results.

\section{Results}

The transcribed material was coded for nine features, which are listed and illustrated from the data in Table 2.

\section{-Table 2 about here-}

In the analysis, an individual could be assigned any number of strategies. However, reuse of the same strategy for one expression was only counted once. That is, if a participant gave two different analogies based on the same phrase, the A category was given a score of I, not 2 for that item. Thus, when the strategy choices were combined for each group, the maximum possible score for each strategy was 17 (one each by the native speakers) and 23 (one each by the non-native speakers). To make these values compatible for calculations and graphs, the scores were turned into percentages (Table 3). It should be kept in mind that percentages can be misleading when the underlying figures are small. For example, a single response by one native speaker counts as $5.89 \%$ whereas a single response from a nonnative speaker is $4.35 \%$.

-Table 3 about here-

\footnotetext{
${ }^{4}$ This task has no formal status in language testing and we cannot by any means take it that increased performance in this task would exactly mirror a wider measure of proficiency. However, we will treat their test performance as a proxy for proficiency for the purposes of this account.

${ }^{5}$ The meanings of the expressions are given in Appendix 3.
} 
Many of the values are small - that is, a strategy was used occasionally, by one or two people. As it is important not to read too much into such occurrences, the discussion below will focus on those strategies that figured most prominently: drawing on context (C), identifying analogies (A), and focussing on unknown items (LT). The category $L$ (links to lexis outside the target) involves several sub-types of response, and will not be discussed here for lack of space.

\section{I The role of context}

-Figure 2 around here-

Just as in Zuo's (2008) study, for both groups, the context was the main basis for working out the meaning. Figure 2 shows that the non-native speakers referred to the context less than the native speakers in all but two cases (at home to a peg and cut a wheedle). The difference in context use between the groups was statistically significant $(t=2.8905, \mathrm{df}=9$, $p=0.0179$, two-tailed).

In order to examine why some items were less reliant on context than others, the ten stimulus expressions were grouped in two ways, according to: (a) the amount of helpful context they had in the surrounding text; (b) the familiarity of the words within them. Examples 3 to 5 illustrate how participants drew on contextual cues in high, medium and low context/transparency environments.

\section{Ex.3}

HIGH CONTEXT, MEDIUM TRANSPARENCY: I think under the hatches must be an expression to mean being under hand, to be working behind the scenes and I think that's because where it says your cousin was a common thief thieves obviously won't do it in plain sight they'll try and do it covertly (NS MLI02)

\section{Ex.4}

MEDIUM CONTEXT, LOW TRANSPARENCY: Not to cut a wheedle with you. l'd say l'd just be thinking that's like well I don't want to fall out with you over this. [The] use of the word cut is quite an aggressive word and then not and you show that they don't want to seem like they're arguing and then where I put it more strongly than that showing that they do that there's some minor disagreement. It's kind of like they're hedging first (NS FLII2).

\section{Ex.5}

LOW CONTEXT, HIGH TRANSPARENCY: I think [handle the ribbons] means an ability to handle some difficulties because the word handle makes me feel like oh it should be something that hard to deal with and I think in the previous sentence like greater importance so I assume that it should be something really important and probably not something easy to do (NS FL204). 
Figures 3 and 4 show that there was no particular tendency for passages with greater or lesser contextual information, and greater or lesser transparency, to affect how much the context was relied on.

--Figures 3 and 4 around here-

\subsection{Analogy}

The native speakers were more likely than the non-native speakers to come up with analogies as a way of determining a meaning. Examples 6 to 9 show that analogies were typically in the form of another idiomatic expression.

\section{Ex.6}

I think never had a feather to fly with must mean the same thing as didn't have two coins to rub together (NS MLI02)

\section{Ex.7}

Handle the ribbons it sounds very much like to know the ropes so I assume it means the same thing (NNS FL208)

\section{Ex.8}

[At home to a peg] it's funny, sometimes other idioms come to mind so to a tee whereas it's nothing really to do with that I don't think. It's just words, phrases of a similar structure come to mind (NS FLI I8)

\section{Ex.9}

So under the hatches so like under the wing maybe or over-protected in this context because or like um yeah over-protected so he never really got into contact with any like crime or whatever so he doesn't steal under the hatches maybe he was his parents or whatever not letting him take part in the you know youth culture or whatever it is (NNS ML209)

Figure 5 compare the use of analogy by the two groups. The difference was statistically significant $(t=3.0393, d f=9, p=0.014)$.

\section{-Figure 5 around here-}

One reason for the greater use of analogy by native speakers might be their greater familiarity with alternative ways of expressing an idea. If so, then we would expect to find an increase in the use of analogy in the non-native speakers according to increasing proficiency. A Spearman's rank correlation test was used to establish whether there was a relationship between proficiency and the amount of analogy used. The result was highly significant $(R=$ $0.66538, p=0.00053)$. This finding suggests that as non-native speakers come closer to native-like competency, they increasingly draw on analogy to help them work out the 
meaning of an unknown expression. Analogy has long been cited as a major means by which effective language learning takes place (e.g. Rumelhart and McClelland, 1986). ${ }^{6}$

\subsection{Admitting to unknown words}

It might seem obvious that, when trying to work out the meaning of an expression, one would mention any individual words that one either was not familiar with, or that one did not believe could have their usual meaning (Examples 10 to I2).

\section{Ex. 10}

I don't know what brown could mean but l'm guessing it means you're being too forward (NS FLI03)

\section{Ex. I I}

Wheedle, what is that? Is it something to sew? (NNS FL207)

\section{Ex. 12}

Culp, I have no idea what that means. Maybe it's load or something (NNS ML209)

Although both groups did refer to unknown words, there was a striking difference in how often. Of the 170 possible opportunities for the 17 native speakers to respond in this way across the 10 stimuli, only four featured this strategy (2.35\%). For the 23 non-native speakers, there were $28 / 230$ instances (12.17\%). Of course, not all of the expressions contained a word that was unknown. Having said that, none of the expressions was actually transparent, which means that there was potential for the meaning of any word to be questioned. In the final section, we discuss in more depth what might lie at the heart of the differences in the approaches to decoding taken by the native and non-native speakers.

\section{Discussion}

The power of language lies in our capacity to understand sentences we have never seen before. By definition, a new word string is not familiar or formulaic and this means that we do not have any opportunity to look it up as a single lexical entry and find a meaning for it as a whole. ${ }^{7}$ Instead, we need to work out its meaning, and, as noted earlier, we will do this by bringing together two types of information: internal semantics and context.

Where the two agree - that is, the direct meaning of the word string fits the context - we will take the meaning to be literal. Where there is a conflict, we will usually believe the context and look for an alternative, figurative meaning. Thus, the expression have no feather to fly with cannot be taken literally in the context of describing a human-for even though it

\footnotetext{
${ }^{6}$ However, when Zuo (2008) compared the strategies used on unknown English idioms with more and less direct equivalents in Chinese, she found no major differences, suggesting that analogy was not playing a major part for her participants.

${ }^{7}$ Technically this is not quite true, because a formulaic frame could be populated with novel slot-fillers, e.g. The Emperor penguin pulled the snail's leg. A truly novel sentence is one that does not deploy a formulaic frame, e.g. Leave seven potatoes and sign the undertaking. Having said that, emergent grammar models hold that any grammatical sentence is based on a frame. But this need not concern us here, because our focus is on the semantics rather than the grammar.
} 
is literally true, it is not a relevant observation to make, pragmatically. Consequently, the reader will infer that it is a figurative expression, and the interpretation assigned will be based on finding a parallel meaning (Example I3).

\section{Ex.13}

I'd say that's like a big exaggeration trying to say that he's never even had a feather to fly with so like why would he have any money to do anything when he never even had something of little value like a feather that's going to help him along (NS FLI I2).

When participants could make no sense of the expression either literally or figuratively because it contained an unknown word or because the words, though recognisable, could not be assigned a relevant meaning, they ranged wide in their attempts to come up with an interpretation. Where words had more than one potential meaning, they struggled to know which one to favour. For example, several respondents were unsure whether to read yard as a measurement or as a place, and bustle as part of a woman's clothing or as 'busyness'.

What might determine when a word was trusted to have its typical meaning (albeit then used figuratively) and when it was not? Why was a participant likely to decide that cut did mean cut but that wafer, bustle and brown might not mean what they appeared to? If we consider the full set of words that variously caused difficulty for the participants (hatches; peg; culp; wafer; brown; wheedle; yard; tin; ribbons; bustle) we find that they are all nouns and adjectives except culp, which no one would have known. Of the words that might have caused problems, but that were taken at face value (under; at home; feather; fly; do; cut; handle; cry; rope; drawing), two are nouns, one is a preposition, one is a prepositional phrase; the remaining six are verbs. So it may be that when we encounter an unknown expression, we tend to place more faith in the meaning of verbs than nouns. Certainly, it is recognised that not all parts of speech are the same in terms of how we process them (Wray, 2015: 749).

Finally, we return to the finding that native speakers were less likely to mention words they didn't know the meaning of. What does this signify? Several explanations are possible. One is that they encountered fewer unknown words in the first place. However, this cannot be the whole explanation. Focussing on the two examples containing words that would have been unknown to all participants, culp a wafer and cut a wheedle, the difference persists. Although there were 34 opportunities for native speakers to mention not knowing one of the words, the admission was made only twice (5.88\%). In contrast, in the non-native group the incidence was $14 / 46$ (30.43\%).

A second possible explanation relates to confidence, though with two possible consequences. One is that the native speakers had more confidence than the non-native speakers about words unknown to them being genuinely difficult to know. If so, they might have taken it as read that they didn't need to tell the interviewers (native speakers) that they didn't know the word. The other possibility is that the native speakers lacked the confidence to admit not knowing the meaning of a word in their own language, whereas the non-native speakers were more accustomed to saying that they did not know an item. 
The third potential explanation is that the lower incidence of mentioning unknown words is linked to the native speakers' greater use of context. In a study of reading habits, Hulstijn (1993) found that second language learners looked up fewer unknown words if the context provided them with sufficient information to allow them to proceed without glossing them. This represents a version of what Wray (2002) terms 'needs only analysis' - only break down material if you have to. What we may be seeing here is that native speakers had greater trust in their interpretation of the context to patch up any lack of knowledge about words, while the second language learners were likely to want the word to elucidate their interpretation of the text as a whole. If so, then we are brought full circle, back to the research literature on formulaic language. It was noted earlier that in our first language we may deal in larger units, and that second language learning, particularly after childhood and/or in a classroom, encourages a greater focus on the internal make up of word strings. If so, then it would follow that the non-native speakers, flummoxed by an expression, would home in on the word they didn't know, and talk about it. The native speakers, on the other hand, may simply not have seen any significance in not knowing the word when they have already realised that they don't know the phrase in its context.

In sum, there are some indications of it being a mark of one's knowledge of, and confidence in, a language, that one can transcend individual items within an unknown phrase, to deduce meaning from the context and through analogy. Meanwhile, the fact that the non-native speakers increasingly approximated this pattern according to their greater familiarity with the target language - at least as measured by the capacity to complete common idiomatic expressions - contradicts the supposition that post-childhood language learners remain different from native speakers in their approach to language processing, even when they command the second language to a very high level.

\section{References}

Bergen, Benjamin K. (200I). 'Nativization processes in LI Esperanto.' Journal of Child Language 28: 575-595.

Dąbrowska, Ewa and Lieven, Elena. (2005) Towards a lexically specific grammar of children's question constructions. Cognitive Linguistics 16: 437-474.

Grice, H. Paul (1975). 'Logic and Conversation.' Syntax and Semantics, vol.3. Ed. P. Cole and J. L Morgan. New York: Academic Press, 4I-58.

Hodge, Jane Aiken. (1984) The private world of Georgette Heyer, London: Bodley Head.

Hulstijn, Jan H. (1993). When do foreign-language readers look up the meaning of unfamiliar words? The influence of task and learner variables. Modern Language Journal, 77 (2): I39147.

Laval, Virginie and Bernicot, Josie. (2002). "Tu es dans la lune": Understanding idioms in French-speaking children and adults. Pragmatics I2 (4): 399-4I3.

Laufer, Batia and Ravenhorst-Kalovski, Geke C. (2010) Lexical threshold revisited: lexical text coverage, learners' vocabulary size and reading comprehension. Reading in a Foreign Language 22: 15-30.

Lieven, Elena, Behrens, Heike, Speares, Jennifer and Tomasello, Michael. (2003) Early syntactic creativity: a usage-based approach. Journal of Child Language 30: 333-370.

MacKenzie, lan. (20I4). English as a lingua franca: theorizing and teaching English. London: Routledge. 
Moon, Rosamund. (1998) Fixed expressions and idioms in English: a corpus-based approach, Oxford: Clarendon Press.

Nippold, Marilyn A. (2006) Language development in school-age children, adolescents and adults. In: Brown K (ed) Encyclopedia of language and linguistics. Oxford: Elsevier, 368-373.

Partridge, Eric. (1973) Routledge dictionary of historical slang, 6 ed, London: Routledge.

Peters, Ann M. (1983) Units of Language Acquisition., Cambridge: Cambridge University Press.

Rumelhart, David E. and McClelland, James L. (1986) On learning the past tenses of English verbs. In: Rumelhart DE and McClelland JL (eds) Parallel distributed processing: explorations in the microstructure of cognition, vol. 2: psychological and biological models. Cambridge, MA: MIT Press, 216-27I.

Seidlhofer, Barbara. (20II) Understanding English as a lingua franca. Oxford: Oxford U P. Taylor, John R. (2012) The mental corpus, Oxford: Oxford University Press.

Tomasello, Michael. (2003) Constructing a Language: A Usage-Based Theory of Language, Cambridge, MA \& London: Harvard University Press.

Vulchanova, Mila, Vulchanov, Valentin and Stankova, Margarita. (20II) Idiom comprehension in the first language: a developmental study. Vigo International Journal of Applied Linguistics 8: 207-234.

Wray, Alison. (2002) Formulaic language and the lexicon. Cambridge: Cambridge University Press.

Wray, Alison. (2008a) Formulaic language: pushing the boundaries, Oxford: Oxford University Press.

Wray, Alison. (2008c) The puzzle of language learning: from child's play to 'linguaphobia'. Language Teaching 4I: 255-273.

Wray, Alison. (2015) Why are we so sure we know what a word is? In: Taylor JR (ed) Oxford Handbook of the Word. Oxford: Oxford University Press, 726-750.

Wray, Alison and Grace, George W. (2007) The consequences of talking to strangers: Evolutionary corollaries of socio-cultural influences on linguistic form. Lingua I 17: 543578.

Wray, Alison and Namba, Kazuhiko. (2003) Formulaic language in a Japanese-English bilingual child: a practical approach to data analysis. Japanese Journal for Multilingualism and Multiculturalism 9: 24-5I.

Zuo, Hongshan. (2008). Comprehension of unfamiliar English idioms by Chinese EFL learners in reading. Journal of the Chinese English Language Association 31 (3): 9-29, http://www.celea.org.cn/teic/79/08080I_9.pdf 
Appendix I: English idiom familiarity test

Name:

Age:

First language:

Other L2s:

Use the two words in the middle to write a phrase that fills the gap in the sentence. You can change the words, or add more words, to make a complete phrase.

\section{Example:}

I think I [MAKE, MISTAKE] in my exam yesterday. made a mistake

I. I'm not sure, but [FAR, KNOW] Heathrow is the busiest airport in Europe.

2. Jane is I0 years old this year. [SEEM, YESTERDAY] that she was a baby.

3. Listen to Martin reading! [HARD, BELIEVE] he is only five years old.

4. They tried everything, but [NO, AVAIL].

5. It was such a surprise. At first I couldn't [TAKE, BOARD]

6. At first I didn't recognise him, but [TURN, OUT] we went to the same college years ago.

7. Anyway, [STORY, SHORT] we missed the bus.

8. [FOR, KNOW] it could be something completely different.

9. [CHANCE, ARE] it won't happen.

10. Call the police. You can't [LAW, HANDS]

II. She started at the bottom of the company, but [WORK, WAY]

12. She's only a young child. That book [OVER, HEAD]

I3. A: You're singing that song again. B: I know. I can't [GET, HEAD]

I4. [LINE, WORK] are you in, John?

I5. It's [LITTLE, CONCERN] to them. 


\section{Appendix 2: Stimuli}

\section{1}

'What could there be that anyone should want?'

'I don't know, but l'll swear there is something. Of course, it may not be a paper; I wonder if Eustace had stolen something of value? He was always under the hatches, and -'

'I will not allow it to be possible!' said Elinor. 'Do you wish me to believe that your cousin was a common thief?'

2

Peter was at home to a peg, for this was his village of boyhood memory. He recalled days on the wing spent in the company of his late grand-uncle from that sunny place, and his own father who, carting his load of turnips to the city markets, had often brought him with him, seated in a special hollow made amongst the turnips. The joy was his when they stayed overnight at Mrs Molloy's lodging house in the haymarket.

3

'Are you imagining that you have become a rich woman overnight?' Carlyon enquired. 'I wish it may be so, but I fear it will be no such thing. You are more likely to discover that you are liable for God knows how many debts.'

'Lord, yes!' said Nicky cheerfully. 'Eustace never had a feather to fly with!'

4

'You enjoy shooting then?' Freddy was saying as he sipped his wine.

'For the pot, yes,' Dick agreed easily. 'Can't see the point in it otherwise. Waste of powder and shot.'

'Are you a good shot then, sir?' Rookwood asked, leaning forward slightly to look down the table at him.

'Passable,' Turpin replied vaguely.

'Come, Richard, you can culp a wafer with the best of them,' Glenrae put in deliberately.

5

Her eyes began to dance, and her lips to quiver. 'You know, you are the most provoking creature I ever encountered!' she told him.

'Oh, come, now, that's doing it rather too brown!' he expostulated. 'Remember, I was acquainted with your brother Rowland!'

6

'It's very good of you to say so, Duke!' responded Sir Nugent, acknowledging the tribute with a slight bow. 'I don't mind admitting it wasn't easy. It took a lot of effort. If there is a thing I pride myself on it's that. 'Lady Henry,' I said - well, not to cut a wheedle with you, Duke, I put it more strongly than that! 'My love,' I said, 'we shan't make him happy if we keep His Lordship waiting at the rendezvous. Take my word for it!' She did.'

7

In the years around 1776, there was a tollgate at Botley Hill, at a place called Coldharbour Beeches. The road was lined with beech trees on each side, and ran along the boundary of the nearby parish of Tatsfield, near the borders of Kent and Surrey. The toll gate cottage is still standing, and still occupied, but the toll gate, which could have blocked the road, has long since gone. The name of the cottage is now Paygate cottage. Stagecoaches paid toll, but 
mail coaches did not. At a blast on the yard of tin, the toll gatekeeper would hurl himself out to open the gate, as the coach thundered through. Every type of traffic gave way to the mail coach.

8

There is now no branch of a lad's outdoor education of greater importance, not only to himself, but also to others, than that of an ability to handle the ribbons.

9

'All right, be bloodthirsty if you must. Boys will be boys. That leaves only the question-who and how do we handle disposing of the wretched girl?'

'That's two questions. I don't know how to do it, but I do know who. I've thought this out most carefully. We both do the deed. That way neither of us is apt to cry rope on the other.'

There was a short silence while his co-conspirator weighed his latest suggestion.

10

When the cloth had been removed, and the brandy placed on the table, Stacy said, with his air of rueful frankness: 'I must tell you, sir, that I was devilish glad to get your letter! I've been drawing the bustle a trifle too freely.' 


\section{Appendix 3: Meanings of stimulus phrases}

(sources: http://www.georgette-heyer.com/slang.html;

http://candicehern.com/regency-world/glossary/

http://www.regencyassemblypress.com/Regency_Lexicon.html

- Under the hatches - in debt

- at home to a peg - very at home

- have no feather to fly with - have no money

- culp a wafer - hit a small object (wafer)

- do it too brown - overdo it, so it's not credible

- cut a wheedle - ingratiate self with someone by lying

- yard of tin - post horn

- handle the ribbons - drive a coach or carriage

- cry rope on - give [someone] away; tell secret

- draw the bustle too freely - spend too much money 
Table I: Expressions used in the study

\begin{tabular}{lll}
\hline Expression & Figurative & $\begin{array}{l}\text { Unknown } \\
\text { word in LI }\end{array}$ \\
\hline under the hatches & $\checkmark$ & X \\
\hline at home to a peg & $\checkmark$ & X \\
\hline [not have a] feather to fly with & $\checkmark$ & X \\
\hline culp a wafer & X & $\checkmark$ \\
\hline do[ing] it rather too brown & $\checkmark$ & X \\
\hline [not] to cut a wheedle with you & $\checkmark$ & $\checkmark$ \\
\hline the yard of tin & X & X \\
\hline to handle the ribbons & $\checkmark$ & X \\
\hline to cry rope on & $\checkmark$ & X \\
\hline draw[ing] the bustle [a trifle] too freely & $\checkmark$ & $(\checkmark)$ \\
\hline
\end{tabular}


Table 2: Coding of responses (NS = native speaker; NNS = non-native speaker)

C Use of context to work out the meaning, e.g. 'they're on about shooting ... maybe culp a wafer is shooting a good shot' (NS FLI03)

LT Mentioning that one of the lexical items in the target expression was not known, or evidently had a different meaning from a known one, e.g. 'I don't know what a peg is' (NNS EJF)

\begin{tabular}{|c|c|}
\hline $\mathrm{A}$ & $\begin{array}{l}\text { Pinning down meaning by means of an analogy, e.g. 'doing it rather too brown is that's rich } \\
\text { coming from you' (NS MLIOI); see also the example under P. }\end{array}$ \\
\hline $\mathrm{L}$ & $\begin{array}{l}\text { Making conceptual links using lexis not in the target, e.g. [feather to fly with] 'Maybe birds } \\
\text { or something like that' (NNS FL209) }\end{array}$ \\
\hline$P$ & $\begin{array}{l}\text { Making a phonological link with one of the words in the target expression, e.g. 'under } \\
\text { the hatches ... I know in modern day we say bury the hatchet' (NS FLI03) }\end{array}$ \\
\hline$M$ & $\begin{array}{l}\text { Creating or extending a metaphor, e.g. 'take the reins, handle the ribbons, yeah, } \\
\text { importance of leadership' (NS FLIII) }\end{array}$ \\
\hline GP & $\begin{array}{l}\text { Commenting on grammar, semantics, pragmatics or some other mechanism for } \\
\text { working it out, e.g. 'So that 'for' explains the reason why he was at home to a peg' (NNS } \\
\text { SSB) }\end{array}$ \\
\hline DK & Giving up, e.g. 'I'm not quite sure about this phrase' (NNS FL22I) \\
\hline TR & $\begin{array}{l}\text { Translation from another language, e.g. 'in terms of my first language German maybe } \\
\text { wafer could be something like weapon, Waffe' (NNS ML209) }\end{array}$ \\
\hline
\end{tabular}


Table 3: Occurrence of each strategy type (percentages)

\begin{tabular}{|c|c|c|c|c|c|c|c|c|c|c|}
\hline & & C & LT & $\mathbf{A}$ & $\mathbf{L}$ & $\mathbf{P}$ & $\mathbf{M}$ & GP & DK & TR \\
\hline \multirow{2}{*}{ Culp a wafer } & Native & 100 & 11.76 & 5.89 & 0 & 5.89 & 0 & 5.89 & 0 & 0 \\
\hline & Non-native & 91.3 & 56.52 & 13.04 & 0 & 0 & 0 & 8.7 & 8.7 & 0 \\
\hline \multirow{2}{*}{ Under the hatches } & Native & 88.24 & 5.89 & 52.94 & 29.41 & 0 & 0 & 0 & 0 & 0 \\
\hline & Non-native & 76.26 & 47.82 & 17.39 & 8.7 & 4.35 & 0 & 4.35 & 4.35 & 4.35 \\
\hline \multirow{2}{*}{ At home to a peg } & Native & 82.35 & 35.29 & 52.94 & 47.06 & 0 & 0 & 0 & 5.89 & 0 \\
\hline & Non-native & 86.96 & 60.87 & 13.04 & 17.39 & 4.35 & 0 & 4.35 & 8.7 & 0 \\
\hline \multirow{2}{*}{ Feather to fly with } & Native & 94.12 & 41.18 & 47.06 & 0 & 0 & 11.76 & 0 & 0 & 0 \\
\hline & Non-native & 86.96 & 52.17 & 4.35 & 4.35 & 0 & 4.35 & 4.35 & 0 & 4.35 \\
\hline \multirow{2}{*}{ Do it too brown } & Native & 88.24 & 41.18 & 5.89 & 5.89 & 11.76 & 0 & 0 & 0 & 0 \\
\hline & Non-native & 82.61 & 52.17 & 4.35 & 0 & 4.35 & 0 & 0 & 8.7 & 8.7 \\
\hline \multirow{2}{*}{ Cut a wheedle } & Native & 76.47 & 17.65 & 41.18 & 0 & 0 & 0 & 0 & 5.89 & 0 \\
\hline & Non-native & 82.61 & 39.13 & 17.39 & 0 & 4.35 & 0 & 4.35 & 4.35 & 4.35 \\
\hline \multirow{2}{*}{ Yard of tin } & Native & 100 & 64.71 & 11.76 & 11.76 & 0 & 0 & 0 & 0 & 0 \\
\hline & Non-native & 86.96 & 73.91 & 0 & 0 & 0 & 4.35 & 0 & 0 & 0 \\
\hline \multirow{2}{*}{ Handle the ribbons } & Native & 70.59 & 82.35 & 35.29 & 0 & 5.89 & 11.76 & 0 & 0 & 0 \\
\hline & Non-native & 65.22 & 78.26 & 26.08 & 0 & 0 & 8.7 & 4.35 & 0 & 0 \\
\hline \multirow{2}{*}{ Cry rope on } & Native & 94.12 & 35.29 & 17.65 & 5.89 & 0 & 0 & 0 & 0 & 0 \\
\hline & Non-native & 86.96 & 91.3 & 17.39 & 0 & 0 & 4.35 & 0 & 0 & 0 \\
\hline \multirow{2}{*}{ Drawing the bustle } & Native & 100 & 41.18 & 11.76 & 5.89 & 5.89 & 0 & 0 & 0 & 0 \\
\hline & Non-native & 86.96 & 39.13 & 0 & 0 & 8.7 & 0 & 4.35 & 8.7 & 0 \\
\hline
\end{tabular}




\section{List of figures}

Figure I: Non-native speaker scores on the English idiom familiarity test

Figure 2: Use of context to interpret expressions

Figure 3: Use of context, grouped by amount of context available

Figure 4: Use of context, grouped by transparency of lexis

Figure 5: Use of analogy to work out meaning 